\title{
A randomized, controlled trial of spinal endoscopic adhesiolysis in chronic refractory low back and lower extremity pain [ISRCTN
} I65586 I 7]

\author{
Laxmaiah Manchikanti*1, Mark V Boswell ${ }^{2}$, Jose J Rivera1, \\ Vidya Sagar Pampati ${ }^{1}$, Kim S Damron ${ }^{1}$, Carla D McManus ${ }^{1}$, \\ Doris E Brandon ${ }^{1}$ and Sue R Wilson ${ }^{1}$
}

\begin{abstract}
Address: ${ }^{1}$ Pain Management Center of Paducah, 2831 Lone Oak Road, Paducah, Kentucky, 42003, USA and ${ }^{2}$ Case University School of Medicine, University Hospitals of Cleveland, 11100 Euclid Avenue, Cleveland, OH, 44106, USA

Email: Laxmaiah Manchikanti* - drm@apex.net; Mark V Boswell - boswellmv@earthlink.net; Jose J Rivera - Rivera@thepainmd.com; Vidya Sagar Pampati - Sagar@thepainmd.com; Kim S Damron - Kim@thepainmd.com; Carla D McManus - Carla@thepainmd.com; Doris E Brandon - Doris@thepainmd.com; Sue R Wilson - Sue@thepainmd.com

* Corresponding author
\end{abstract}

Published: 06 July 2005

BMC Anesthesiology 2005, 5:10 doi: 10.1 | 86//47|-2253-5-10
Received: 08 November 2004

Accepted: 06 July 2005

This article is available from: http://www.biomedcentral.com/I47I-2253/5/10

(c) 2005 Manchikanti et al; licensee BioMed Central Ltd.

This is an Open Access article distributed under the terms of the Creative Commons Attribution License (http://creativecommons.org/licenses/by/2.0), which permits unrestricted use, distribution, and reproduction in any medium, provided the original work is properly cited.

\begin{abstract}
Background: Postoperative epidural fibrosis may contribute to between $5 \%$ to $60 \%$ of the poor surgical outcomes following decompressive surgery. Correlations have been reported between epidural scarring and radicular pain, poor surgical outcomes, and a lack of any form of surgical treatment. The use of spinal endoscopic adhesiolysis in recent years in the management of chronic refractory low back and lower extremity pain has been described.

Methods: A prospective, randomized, double-blind trial was conducted to determine the outcome of spinal endoscopic adhesiolysis to reduce pain and improve function and psychological status in patients with chronic refractory low back and lower extremity pain. A total of 83 patients were evaluated, with 33 patients in Group I and 50 patients in Group II. Group I served as the control, with endoscopy into the sacral level without adhesiolysis, followed by injection of local anesthetic and steroid. Group II received spinal endoscopic adhesiolysis, followed by injection of local anesthetic and steroid.

Results: Among the 50 patients in the treatment group receiving spinal endoscopic adhesiolysis, significant improvement without adverse effects was shown in $80 \%$ at 3 months, $56 \%$ at 6 months, and $48 \%$ at 12 months. The control group showed improvement in $33 \%$ of the patients at one month and none thereafter. Based on the definition that less than 6 months of relief is considered short-term and longer than 6 months of relief is considered long-term, a significant number of patients obtained long-term relief with improvement in pain, functional status, and psychological status.

Conclusion: Spinal endoscopic adhesiolysis with targeted delivery of local anesthetic and steroid is an effective treatment in a significant number of patients with chronic low back and lower extremity pain without major adverse effects.
\end{abstract}




\section{Background}

Postoperative epidural fibrosis, the formation of dense scar tissue adjacent to the dura mater following surgical laminectomy, may play a role in up to $60 \%$ of the poor surgical outcomes following decompressive surgery [1-3]. A correlation between peridural scarring and radicular pain [4-7], and poor clinical outcomes [8,9] has been reported by some, while others [10-13] have questioned the role of epidural fibrosis as a causative factor. Increased complication rates have been reported with revision spine surgery with increased occurrence of dural tears, nerve root injury, and bleeding $[14,15]$. Phillips and Cunningham [16] reported that no form of surgical treatment or adhesion lysis procedure was safe or effective for postlumbar laminectomy syndrome.

Epidural fibrosis results from the invasion of postoperative hematoma by dense fibrous tissue originating from the periosteum and within the deep surface of the paravertebral musculature $[17,18]$. Epidural fibrosis may extend into the neural canal and adhere to the dura mater and nerve roots, with mechanical tethering of nerve roots or dura by adhesions, which may in turn contribute to persistent back and leg pain following lumbar laminectomy. However, epidural fibrosis also may develop without surgical intervention, secondary to annular tear, hematoma, infection, or intrathecal contrast media [18-20]. Perineural fibrosis can render nerve roots hyperesthetic and hypersensitive to compression forces by interfering with cerebrospinal fluid-mediated nutrition [6] or by making the nerve susceptible to injury [7].

A moderate proportion of patients show improvement in pain and functional level with interventional pain management procedures, including fluoroscopically-directed epidural steroid injections and percutaneous adhesiolysis utilizing a special catheter $[21,22]$. In addition, initial clinical studies of spinal endoscopic adhesiolysis [23-29] and a preliminary report of a randomized controlled trial [30] showed improved clinical outcomes. However, a recent prospective, randomized, double-blind trial [31] comparing caudal epidural with targeted steroid placement on affected nerve roots during spinal endoscopy for chronic sciatica, concluded that targeted placement of steroid did not significantly reduce pain intensity and anxiety and depression compared with caudal epidural steroid injection.

Most studies utilized post lumbar laminectomy syndrome or epidural fibrosis as inclusion criteria, whereas one study [28] included patients with lumbar spinal stenosis, and another [31] exclusively studied patients without history of surgery. In addition, some studies $[26,27,30]$ specifically described inclusion criteria as patients without long-term improvement following fluoroscopically directed epidural steroid injections and one-day percutaneous adhesiolysis. Consequently, these studies represent heterogenous populations. Even though retrospective evaluations $[26,27]$ have shown the effectiveness of spinal endoscopic adhesiolysis in patients after lack of long-term effect following fluoroscopically-directed caudal epidural steroid injections and one-day percutaneous adhesiolysis, the effectiveness has not been demonstrated in controlled trials.

Spinal endoscopy also has been utilized for diagnostic purposes. Even though multiple authors have described various types of findings, including the identification of inflammation with an endoscope, neither the reliability nor the clinical utility of spinal endoscope as a diagnostic tool has been established [23-25,28,29]. Consequently, no attempt was made to evaluate the diagnostic utility of spinal endoscopy.

This randomized, double-blind, controlled trial of spinal endoscopic adhesiolysis and targeted delivery of steroids was designed to evaluate their effectiveness in patients with chronic low back and lower extremity pain who lacked significant response to fluoroscopically-directed epidural steroid injections and one-day percutaneous adhesiolysis with hypertonic saline neurolysis, as well as to other conservative modalities of treatment.

\section{Methods}

This study was designed to evaluate the effectiveness of spinal endoscopic adhesiolysis in chronic, refractory low back and lower extremity pain. The study was undertaken in an interventional pain management practice (a specialty referral center) in a private practice setting, in accordance with the guidelines for randomized controlled trials [32,33], and the quality checklists of systematic reviews [32,34-39]. The trial also was designed to meet criteria of a pragmatic or a practical clinical trial $[30,40,41]$. The protocol was approved by the Institutional Review Board of the Ambulatory Surgery Center where the study was conducted. The objective was to evaluate the effectiveness of spinal endoscopic adhesiolysis compared to caudal epidural steroid injection. The design consisted of a control group and an intervention group. Group I (control group) was treated with introduction of the spinal endoscope up to the S3 level, followed by injection of a local anesthetic and steroid. Group II (intervention group) was treated with appropriate spinal endoscopic adhesiolysis at L4, L5 or S1 level(s) unilaterally or bilaterally based on symptomatology, followed by a targeted injection of local anesthetic and steroid.

\section{Inclusion and exclusion criteria}

The majority of participants in this study were identified from existing patients of the interventional pain 
management practice. Eligible new patients were screened and identified as candidates for the program.

\section{Inclusion criteria}

patients between 18 and 65 years of age with a history of chronic low back and lower extremity pain of at least two year's duration, without facet joint pain based on controlled comparative local anesthetic blocks, and without significant improvement with conservative treatment including fluoroscopically-directed epidural injections and one-day percutaneous adhesiolysis with hypertonic saline neurolysis, and willingness to participate in the clinical trial were enrolled.

Criteria for lack of significant response to caudal epidural steroid injections was pain relief $(\geq 50 \%)$ for one week or less following a second epidural steroid injection, and relief of four weeks or less following a third epidural steroid injection or any of subsequent epidural steroid injections. Criteria for lack of response to one-day percutaneous adhesiolysis with hypertonic saline neurolysis was considered as lack of response to the first adhesiolysis procedure, less than two months of pain relief $(\geq$ $50 \%$ ) following the second or subsequent procedures.

\section{Exclusion criteria}

patients with cauda equina syndrome, compressive radiculopathy, surgical intervention in the previous six months, opioid abuse and dependency evaluated by adherence monitoring, including random drug testing and opioid use of no greater than hydrocodone $100 \mathrm{mg}$ per day, methadone $60 \mathrm{mg}$ or morphine $100 \mathrm{mg}$ or equivalent doses of other drugs; uncontrolled major depression or psychiatric disorders; uncontrolled or acute medical illnesses including severe cardiac, pulmonary, or other disorders; chronic conditions that could interfere with the interpretations of the outcome assessments such as severe hip or knee arthritis, neuropathy, or other disorders; pregnant or lactating women; history of adverse reaction to local anesthetic or steroids; inability to understand the informed consent and protocol; or inability to be positioned in the prone position during the procedure [30].

\section{Evaluation}

All patients were provided with the protocol and the informed consent document approved by the Institutional Review Board for this study. The informed consent document described the details of the trial.

The screening evaluation consisted of demographic data, medical/surgical history with co-existing diseases, radiographic investigations, physical examination, psychological evaluation with Pain Patient Profile $\left(\mathrm{P}-3^{\varpi}\right)$, Visual Analogue Scale (VAS) pain scores, work status, Oswestry Disability Index 2.0, and lumbar spine range of motion with ARCON ROM computerized dual inclinometer system, based on AMA "Guides to the Evaluation of Permanent Impairment" validity criterion utilizing three consecutive measurements with $\pm 5^{\circ}$ or $\pm 10 \%$ of mean value.

\section{Interventions}

All patients in both groups were provided identical preparation. All procedures were performed using fluoroscopy in an ambulatory surgery center in sterile operating rooms by one physician (LM).

\section{Procedure}

The procedure included appropriate preparation with intravenous access, pre-procedure antibiotic administration, sterile preparation, and appropriate sedation with fentanyl and midazolam. Access to the epidural space was obtained with a $\mathrm{RK}^{\circledast}$ needle. An epidurogram was obtained which identified filling defects and/or epidural fibrosis. Adhesiolysis was carried out in the intervention group utilizing the myeloscope $e^{\circledast}$ spinal endoscopic videoguided catheter system and introducer system, with final positioning of the fiberoptic endoscope on the side and level of the defect and the source of pain with an additional injection of contrast to identify adhesiolysis, followed by targeted injection of local anesthetic and steroid.

Following initial epidurography in the control group, a $0.9 \mathrm{~mm}$ guidewire was inserted through the needle, which was advanced under fluoroscopic guidance to S3 level. Then, a $2-\mathrm{mm} \times 17.8-\mathrm{cm}$ dilator with catheter (sheath) was passed over the guidewire again up to S3. At that time, a $0.8-\mathrm{mm}$ fiberoptic spinal endoscopic video-guided system was introduced into the catheter through the valve and was advanced until the tip was positioned at the distal end of the catheter through the valve, as determined by video and fluoroscopic images not to exceed S3. Following this, $10 \mathrm{~mL}$ of $1 \%$ lidocaine and $6 \mathrm{mg}$ to $12 \mathrm{mg}$ of betamethasone or $40 \mathrm{mg}$ to $80 \mathrm{mg}$ of methylprednisolone were injected through the epiduroscope. Following the completion of the procedure, the endoscope was removed and appropriate sterile Bioclusive dressing was applied.

In the intervention group, following initial epidurography, a 0.9-mm guidewire was inserted through the needle (occasionally facilitated by a small incision with a \#11 straight blade), which was advanced under fluoroscopic guidance to the level of suspected pathology. Following this, a $2-\mathrm{mm} \times 17.8-\mathrm{cm}$ dilator with catheter (sheath) was passed over the guidewire. Once the catheter was advanced to the tip of the guidewire, the wire was removed. A $0.8-\mathrm{mm}$ fiberoptic spinal endoscopic videoguided system was introduced into the catheter through the valve and advanced until the tip was positioned at the distal end of the catheter, as determined by video and 
fluoroscopic images. In conjunction with gentle irrigation using normal saline, the catheter and fiberoptic myeloscope were manipulated and rotated in multiple directions, with visualization of the nerve roots at various levels. Painful nerve root was confirmed by endoscopic manipulation, based on pre-procedural clinical and radiographic evaluation. Adhesiolysis and decompression were carried out by distension of the epidural space with normal saline and by mechanical means utilizing the fiberoptic endoscope. Adhesiolysis was confirmed by injection of non-ionic contrast material (Omnipaque $240^{\circledast}$ ) and an epidurogram was performed on at least two occasions. The volume of sodium chloride solution utilized for irrigation was closely monitored. The protocol limited the total volume of contrast and sodium chloride solution not to exceed $100 \mathrm{~mL}$. Adhesiolysis was limited to L4, L5 or S1 levels, either unilaterally or bilaterally. Following completion of the procedure, $4 \mathrm{~mL}$ to $8 \mathrm{~mL}$ of lidocaine $1 \%$, preservative free, mixed with either $6 \mathrm{mg}$ or 12 $\mathrm{mg}$ of betamethasone or $40 \mathrm{mg}$ or $80 \mathrm{mg}$ of methylprednisolone was injected after assuring that there was no evidence of subarachnoid leakage of contrast. The injection of betamethasone or methylprednisolone was based on its availability in the market. Methylprednisolone was utilized if betamethasone was not available. If pathology was identified at multiple levels, the procedure was carried out at those levels, and the injectate was given in divided doses. If there was a question of subarachnoid leakage of the contrast, a Racz catheter ${ }^{\oplus}$ was passed into the epidural space, and a mixture of local anesthetic was injected very slowly in incremental doses, followed by injection of the steroid if satisfactory follow-up was obtained without any subarachnoid blockade. Following the injection of local anesthetic and steroid, the scope was removed and appropriate sterile Bioclusive dressing was applied.

\section{Co-interventions}

No specific co-interventions were offered. Baseline drug therapy was allowed to be continued with no changes being made towards increasing opioids until after the unblinding and/or documented failure of intervention. However, opioid decreases were implemented based on improvement in functional status and reduction in pain following the interventions. Self-directed exercises as tolerated were also prescribed.

\section{Outcomes assessment}

Outcomes were assessed at 3-month, 6-month, and 12month intervals post-treatment with the Visual Analogue Scale (VAS) pain scale, Oswestry Disability Index 2.0, work status, opioid intake, range of motion measurement by ARCON ROM computerized evaluation, and psychological evaluation by P-3. They were compared to baseline within both groups and with each other at various time intervals. Duration of relief was judged to be short-term, if relief was less than 6 months. If relief lasted for at least 6 months, it was considered long-term. Significant relief was defined as pain relief of $50 \%$ or greater.

VAS was measured on a $10 \mathrm{~cm}$ scale. P-3 psychological evaluation [42] and Oswestry Disability Index 2.0 [43] were assessed by administration of appropriate questionnaires. Range of motion was evaluated by a certified physical therapist, blinded to the type of treatment. Based on P-3, scores of 55 or higher were considered positive for a diagnosis of depression, whereas, scores of 56 or higher were considered to provide the diagnosis of anxiety or somatization.

Opioid intake was determined as none, mild, moderate, or heavy based on the dosage, frequency and schedule of the drug as follows: Considered as mild was an intake of Schedule IV opioids, i.e., propoxyphene napsylate, pentazocine hydrochloride, tramadol hydrochloride up to a maximum of four times, or hydrocodone less than $40 \mathrm{mg}$ per day; considered moderate was an intake of Schedule III opioids, i.e., hydrocodone, up to $40 \mathrm{mg}$ per day; and considered heavy was an intake of Schedule II opioids, i.e., oxycodone, morphine, meperidine, transdermal fentanyl, and methadone, in any dosage.

Employment and work status (employed, unemployed, housewife, disabled, and retired) were determined from the pre-treatment and post-treatment work status. Only employed and unemployed patients were considered to be eligible for employment, whereas disabled patients and retired patients were considered not employable. Patients in the "housewife" category were considered neither employable nor unemployable.

\section{Statistical methods Study design}

Randomization was 2:3 with two patients randomized to the control group (Group I), for every three patients randomized to the spinal endoscopic adhesiolysis group (Group II). Randomization was performed by the statistician using a computer-generated random allocation sequence in blocks of 15 patients.

The random allocation was concealed from the physician doing the procedure and personnel in the operating room until the intervention. Randomization was not revealed to the personnel in the recovery room or to the reviewing physician. After treatment, the patient was never in contact with anyone with knowledge to the randomization assignment, until after the unblinding was performed.

Unblinding was considered at a patient's request and/or treatment was considered a failure at 3 months or later. All other patients were unblinded at 12 months. Patients 
were also given an option to discontinue or to withdraw from the study for any and all reasons. They were considered withdrawn if follow-up was lost.

\section{Intent-to-treat analysis}

An intent-to-treat analysis was performed by including all subjects by carrying forward the last observation.

\section{Statistical analysis}

Demographic data were analyzed by means of the Student's $t$ test and the chi-squared test. Fischer's exact test was used wherever the expected value was less than five. For analyzing Outcome measurement based on Visual Analogue Scale (VAS) Report and Oswestry Disability Index, range of motion (ROM), depression, anxiety and somatization scores, student's t test (parametric) and The Mann-Whitney U test (non-parametric) were used to test mean differences between groups. A paired t test and Wilcoxon signed-rank test were used to compare pre-and post-treatment results for individual patients. When results from both parametric and non-parametric tests were similar, $P$ values from the parametric tests were reported in the tables and text. Results were considered statistically significant if the $P$ value was less than 0.05 .

\section{Results}

The study was conducted from January 2002 through December 2003. As per the protocol, initial results were published in 2003; this preliminary report included a 6 month follow up with 16 patients in caudal epidural steroid injection group, and 23 patients in spinal endoscopy group [30]. To facilitate this publication, results of two patients in the control group and 12 patients in the intervention group were unblinded by the statistician for purposes of the evaluation and preliminary publication. This unblinding was not revealed to investigators, other staff, and the participants of the study. Consequently, 39 patients reported at 6 months were also included in the present report.

A diagram illustrating flow of the trial is depicted as Figure 1. In the control group, one patient was lost to follow-up after 3 months. In the intervention group, two patients withdrew from the study. One patient experienced no improvement, withdrew from the study, and underwent further surgical intervention. The second patient in the intervention group reported no significant relief and withdrew from the study and refused further follow-up. Intent to treat analysis was performed by using baseline or last follow-up data in both groups. All patients received only one treatment during the study period. Patients were considered withdrawn if they received any other interventional techniques. Last follow-up was utilized for analysis with 3-month data at 6 months and 12 months in 15 patients, and 6-month data at 12 months in two patients in the control group. In the intervention group, baseline data was utilized in two patients. In the intervention group, of the 11 patients unblinded at 3 months, five of them participated in outcomes assessment at 6 months and 12 months while six of them participated only at 6 months assessment. Thus, 3 month assessment results were utilized at 6 months and 12 months, whereas the results of 6 month assessments were utilized at 12 months in eight patients (six patients from 3 month unblinding and two patients from 6 month unblinding).

\section{Demographic characteristics}

Table 1 illustrates the demographic characteristics. All the patients presented with back and lower extremity pain. Most patients had pain with unilateral symptoms, while bilateral symptoms were seen in $12 \%$ of the patients in each group.

\section{Procedural characteristics}

In the control group, of the four patients (12\%) with bilateral back and lower extremity pain, two patients received $12 \mathrm{mg}$ of betamethasone and two patients received $80 \mathrm{mg}$ of methylprednisolone. Of the remaining 29 patients, 16 patients received $6 \mathrm{mg}$ of betamethasone and 13 patients received $40 \mathrm{mg}$ of methylprednisolone. The volume of contrast was $8.6 \pm 1.25 \mathrm{~mL}$ with a range of 8 to $12 \mathrm{~mL}$ (Table 2).

In the intervention group, adhesiolysis was performed bilaterally in six patients $(12 \%)$. Adhesiolysis was performed at one level in two patients, at two levels in 47 patients, and at four levels in one patient. Unilateral adhesiolysis was performed in only one patient at L4 level. No bilateral adhesiolysis was performed at L4. Most commonly, adhesiolysis was performed at L5 and S1. The volume of sodium chloride solution injected was $55.0 \pm$ $11.07 \mathrm{~mL}$ with a range of 35 to $70 \mathrm{~mL}$. The volume of contrast was $11.2 \pm 2.74 \mathrm{~mL}$ with volumes ranging from 8 to $16 \mathrm{~mL}$. There were no cases of subarachnoid blockade identified prior to injection of local anesthetic and steroid. Thus, although it was available as part of the proto$\mathrm{col}$, a Racz catheter was not used for any patient procedure in the study. Twelve milligrams of betamethasone in $8 \mathrm{~mL}$ of $1 \%$ lidocaine was injected in two patients and $80 \mathrm{mg}$ of methylprednisolone in $8 \mathrm{~mL}$ of $1 \%$ lidocaine was injected in four patients, $6 \mathrm{mg}$ of betamethasone in $4 \mathrm{~mL}$ of $1 \%$ lidocaine was injected in 28 patients, and $40 \mathrm{mg}$ of methylprednisolone in $4 \mathrm{~mL}$ of $1 \%$ lidocaine was injected in 16 patients (Table 2).

\section{Outcome measures}

A significant proportion of patients in the spinal endoscopic adhesiolysis group showed pain relief compared to the control group, as well as compared to the baseline findings (Fig 2). 


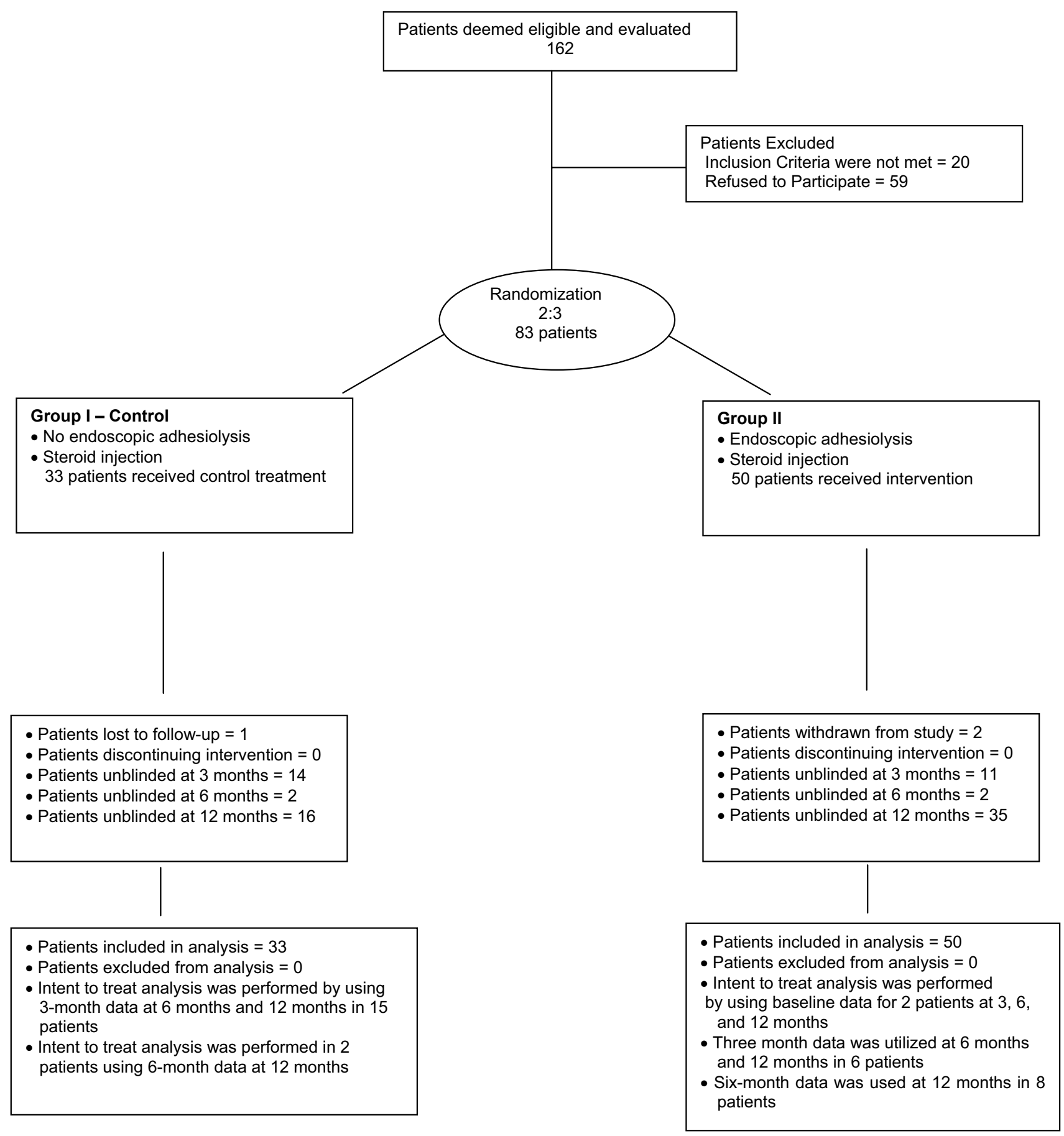

Figure I

Schematic depiction of patient flow during the trial.

Significant pain relief $(\geq 50 \%)$ in months was calculated for both groups. Calculations for all patients showed that significant relief was seen for $0.7 \pm 0.73$ months in the control group, whereas, $7.6 \pm 4.7$ months of relief was noted for the intervention group. Significant pain relief was longer in the intervention group. Duration of significant relief $(\geq 50 \%)$ (mean $\pm S D$ ) was $9.3 \pm 3.6$ months in patients considered as successful ( 40 of 50 ). 
Table I: Demographic characteristics

\begin{tabular}{llcc}
\hline & & Group I & Group II \\
\hline Number of patients & & 33 & 50 \\
Age (Years) & Mean \pm SD & $47 \pm 9.4$ & $50 \pm 9.0$ \\
Gender & Male & $54 \%(18)$ & $36 \%(18)$ \\
& Female & $46 \%(15)$ & $64 \%(32)$ \\
Height (Inches) & Mean \pm SD & $66 \pm 3.6$ & $66 \pm 3.5$ \\
Weight (Lbs) & Mean \pm SD & $181 \pm 42.4$ & $174 \pm 36.8$ \\
Duration of pain (years) & Mean \pm SD & $12.4 \pm 5.9$ & $11.8 \pm 6.5$ \\
Mode of onset of the pain & Traumatic & $39 \%(13)$ & $46 \%(23)$ \\
& Non-traumatic & $61 \%(20)$ & $54 \%(27)$ \\
Back and lower extremity pain & & $100 \%(33)$ & $100 \%(50)$ \\
Bilateral pain & & $12 \%(4)$ & $12 \%(6)$ \\
History of previous surgery & & $73 \%(24)$ & $84 \%(42)$ \\
Epidural fibrosis on MRI & & $73 \%(24)$ & $84 \%(42)$ \\
Disc herniation on MRI & & $12 \%(4)$ & $10 \%(5)$ \\
\hline
\end{tabular}

Table 2: Description of procedural characteristics

\begin{tabular}{|c|c|c|c|}
\hline & & Group I 33 & Group II 50 \\
\hline \multicolumn{4}{|l|}{ Betamethasone } \\
\hline $12 \mathrm{mg}$ & & $6 \%(2)$ & $4 \%(2)$ \\
\hline $6 \mathrm{mg}$ & & $48 \%(16)$ & $56 \%(28)$ \\
\hline Total & & $55 \%(18)$ & $60 \%(30)$ \\
\hline \multicolumn{4}{|l|}{ Methylprednisolone } \\
\hline $80 \mathrm{mg}$ & & $6 \%(2)$ & $8 \%(4)$ \\
\hline $40 \mathrm{mg}$ & & $39 \%(13)$ & $32 \%(16)$ \\
\hline Total & & $45 \%(15)$ & $40 \%(20)$ \\
\hline \multirow[t]{2}{*}{ Contrast in $\mathrm{mL}$} & Mean \pm SD & $8.6 \pm 1.25$ & $11.2 \pm 2.74$ \\
\hline & Range & $8-12$ & $8-16$ \\
\hline \multirow[t]{2}{*}{ Sodium chloride solution for irrigation in $\mathrm{mL}$} & Mean \pm SD & None & $55.0 \pm 11.07$ \\
\hline & Range & & $35-70$ \\
\hline
\end{tabular}

() indicates number of patients

In the control group, the proportion of patients with significant relief greater than $50 \%$ at 1 month was $33 \%$, and at 3 months, 6 months, and 12 months was 0 . By contrast, in the intervention group relief was $90 \%$ at 1 month, $80 \%$ at 3 months, $56 \%$ at 6 months, and $48 \%$ at 12 months (Fig. 3).

Functional outcome measurement was carried out based on Oswestry Disability Index 2.0. Significant improvements were seen in the intervention group compared to baseline in the same group, as well as compared to the control group (Fig. 4).

Analysis of range of motion evaluations showed significant improvements in the intervention group compared to the baseline, as well as the control group at intervals of 3 months, 6 months, and 12 months (Table 3).
Table 4 illustrates psychological outcomes of depression, anxiety, and somatization derived from P-3 scores. Significant improvement was noted in psychological parameters in the intervention group compared to the control group, as well as to baseline status in the treatment group.

Patients were evaluated for opioid intake, which was rated from none to significant as described in the methods section. Significant opioid intake was $40 \%$ in Group II at the end of 12 months, compared to $74 \%$ at baseline. For Group I, significant opioid usage was 55\% at 12 months, compared to $61 \%$ at baseline.

Evaluation of employment status showed that in the intervention group employment increased to $32 \%$ at 12 months from $2 \%$ at baseline as compared to $6 \%$ at base- 


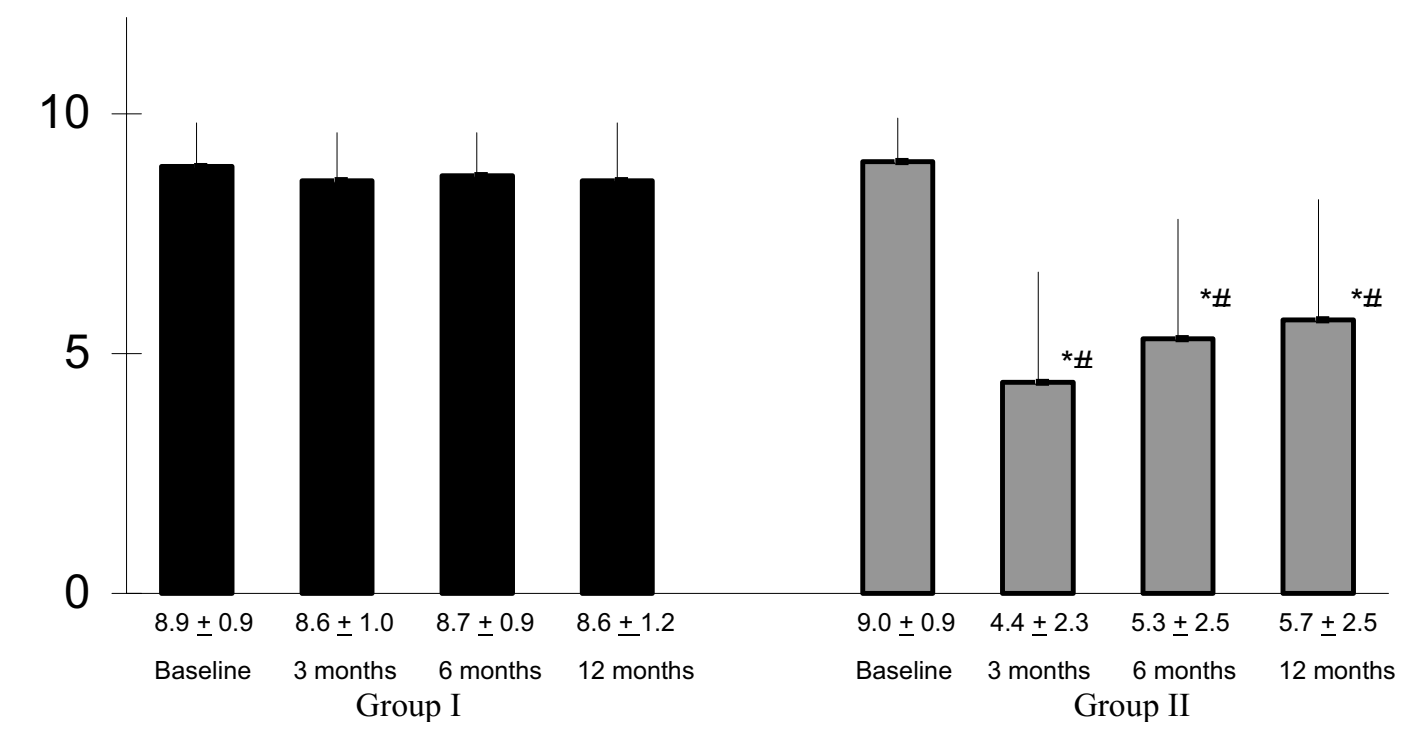

\# Indicates significant difference within the group compared to baseline $(\mathrm{P}=0.001)$

* Indicates significant difference with Group $\mathrm{I}$ at the time of evaluation $(\mathrm{P}=0.001)$

Figure 2

Outcome measurement based on Visual Analogue Scale report.

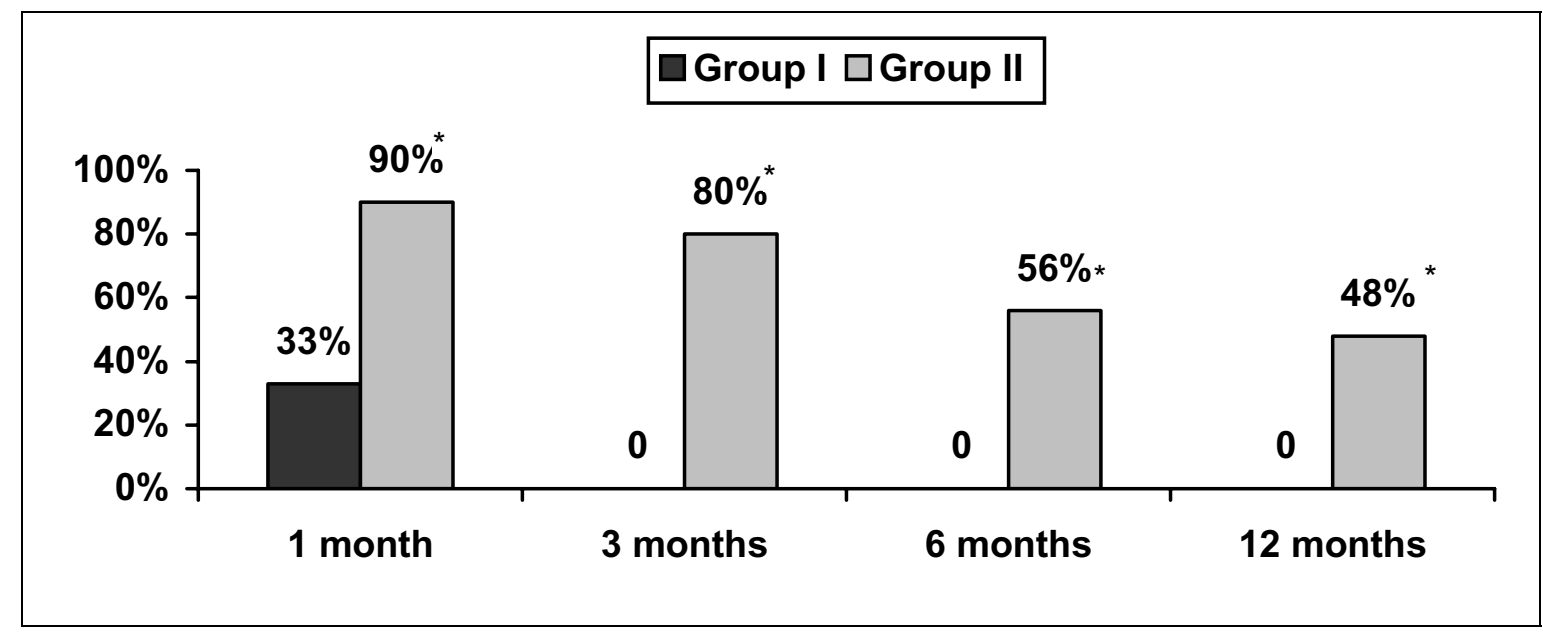

* Indicates significant difference with Group I, at the time of evaluation $(P=0.001)$

Figure 3

Proportion of patients with significant relief $(\geq 50 \%)$ at I month, 3 months, 6 months and 12 months. 


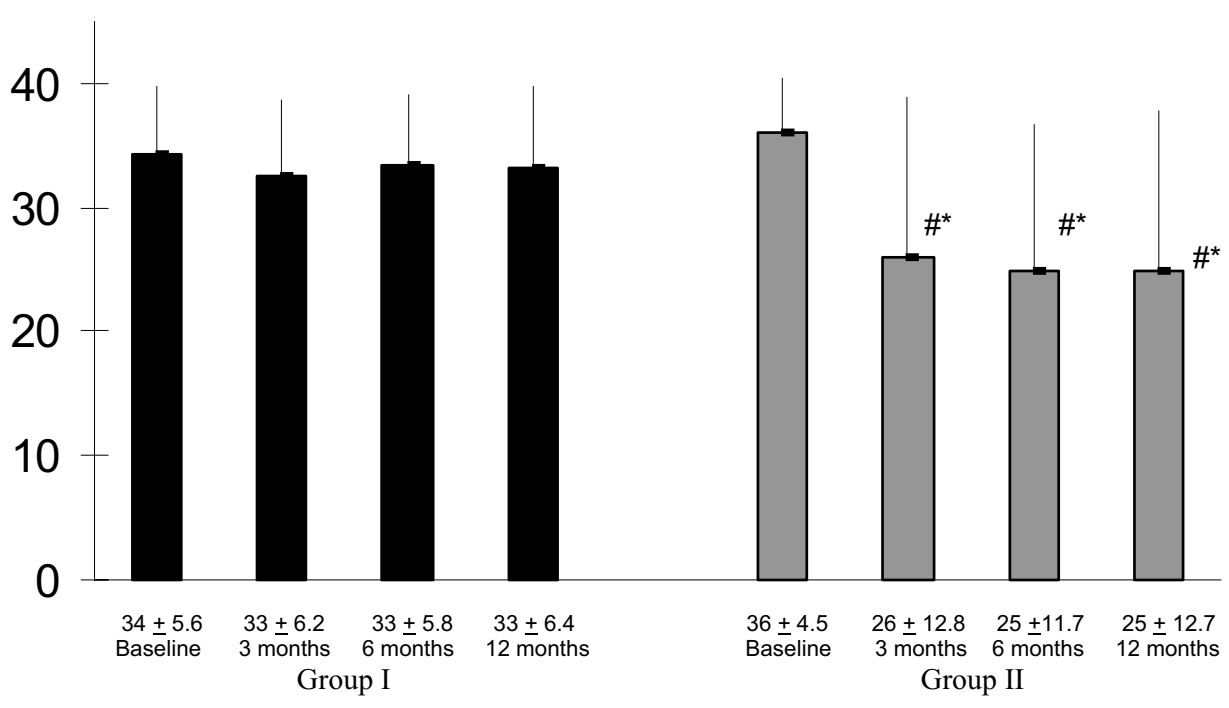

\# Indicates significant difference within the group compared to baseline $(\mathrm{P}=0.001)$

* Indicates significant difference with Group I at the time of evaluation $(\mathrm{P}=0.001)$

\section{Figure 4}

The Outcome Measurement Based on Oswestry Disability Index.

Table 3: Analysis of range of motion evaluation

\begin{tabular}{|c|c|c|c|c|c|c|c|c|c|}
\hline & & \multicolumn{2}{|c|}{ Baseline } & \multicolumn{2}{|c|}{3 months } & \multicolumn{2}{|c|}{6 months } & \multicolumn{2}{|c|}{12 months } \\
\hline & & Group I & Group II & Group I & Group II & Group I & Group II & Group I & Group II \\
\hline & & 33 & 50 & 33 & 50 & 33 & 50 & 33 & 50 \\
\hline $\begin{array}{l}\text { Flexion (Normal } \\
60^{\circ} \text { ) }\end{array}$ & Mean \pm SD & $25.4 \pm 10.0$ & $25.9 \pm 11.4$ & $26.6 \pm 10.3$ & $35.8^{* \#} \pm 11.7$ & $25.8 \pm 10.4$ & $36.7^{* \#} \pm 13.7$ & $25.6 \pm 10.3$ & $35.7^{* \# \pm 14.4}$ \\
\hline $\begin{array}{l}\text { Extension } \\
\left(\text { Normal } 25^{\circ}\right)\end{array}$ & Mean \pm SD & $9.7 \pm 3.9$ & $9.0 \pm 3.3$ & $10.9 \pm 5.1$ & $14.7^{* \#} \pm 5.3$ & $10.5 \pm 5.1$ & $15.8^{* \#} \pm 6.5$ & $10.9 \pm 5.3$ & $16.3^{* \#} \pm 7.0$ \\
\hline $\begin{array}{l}\text { Lateral Flexion } \\
\left(\text { Normal } 25^{\circ}\right)\end{array}$ & Mean \pm SD & $8.1 \pm 2.9$ & $8.4 \pm 2.8$ & $7.9 \pm 3.0$ & $14.0^{* \#} \pm 5.3$ & $7.8 \pm 3.0$ & $14.6^{* \# \pm 6.1}$ & $7.7 \pm 2.8$ & $15.1^{* \# \pm 6.8}$ \\
\hline
\end{tabular}

* Indicates significant difference with Group I $(P=0.002)$

\# Indicates significant difference within the Group compared to baseline $(P=0.001)$

line and at 12 months in the control group. As illustrated in Table 5, almost all the patients deemed employable in the intervention group were employed at 12 months, in contrast to no change noted in the control group. In addition, in the intervention group, eight patients disabled at baseline were also employed at 12 months. There were no patients in this study with active workers' compensation injury cases or litigation.

\section{Blinding}

The blinding was judged to be satisfactory. Following the treatment, and within one hour prior to discharge, 
Table 4: Analysis of psychological status

\begin{tabular}{|c|c|c|c|c|c|}
\hline & & \multicolumn{2}{|c|}{ Baseline } & \multicolumn{2}{|c|}{12 months } \\
\hline & & Group I & Group II & Group I & Group II \\
\hline & & 33 & 50 & 33 & 50 \\
\hline \multirow[t]{2}{*}{ Depression } & Diagnosis $(\geq 55)$ & $61 \%(20)$ & $68 \%(34)$ & $58 \%(19)$ & $34 \% *(17)$ \\
\hline & Score Mean \pm SD & $56.9 \pm 8.8$ & $57.0 \pm 9.9$ & $55.5 \pm 10.6$ & $47.8^{* \#} \pm 10.4$ \\
\hline \multirow[t]{2}{*}{ Anxiety } & Diagnosis $(\geq 56)$ & $58 \%(19)$ & $62 \%(31)$ & $55 \%(18)$ & $28 \% *(\mid 4)$ \\
\hline & Score Mean \pm SD & $55.6 \pm 10.6$ & $55.9 \pm 11.9$ & $54.9 \pm 9.9$ & $46.8^{* \# \pm} \pm 12.1$ \\
\hline \multirow[t]{2}{*}{ Somatization } & Diagnosis $(\geq 56)$ & $58 \%(19)$ & $74 \%(34)$ & $52 \%(17)$ & $30 \%(18)$ \\
\hline & Score Mean \pm SD & $55.4 \pm 8.9$ & $56.6 \pm 11.4$ & $55.9 \pm 10.4$ & $47.8^{* \# \pm 12.3}$ \\
\hline
\end{tabular}

* Indicates significant difference with Group I $(P=<0.05)$

\# Indicates significant difference with Baseline values within the Group $(P=<0.001)$

Table 5: Change in proportion of patients with employment status

\begin{tabular}{|c|c|c|c|c|}
\hline \multirow[t]{2}{*}{ Employment Status } & \multicolumn{2}{|c|}{ Group I } & \multicolumn{2}{|c|}{ Group II } \\
\hline & Baseline & At 12 months & Baseline & At 12 months \\
\hline Employed & $2(6 \%)$ & $2(6 \%)$ & I (2\%) & $16(32 \%)^{*}$ \\
\hline Unemployed & $2(6 \%)$ & $2(6 \%)$ & $8(16 \%)$ & I (2\%) \\
\hline Housewife & $2(6 \%)$ & $2(6 \%)$ & I (2\%) & I (2\%) \\
\hline Disabled & $26(79 \%)$ & $26(79 \%)$ & 38 (76\%) & $30(60 \%)$ \\
\hline Over 65 (yrs) & I (3\%) & I (3\%) & $2(4 \%)$ & $2(4 \%)$ \\
\hline Total & 33 & 50 & 33 & 50 \\
\hline
\end{tabular}

*Indicates significant difference $(P<0.01)$

patients were asked what treatment they believed they had received. Twenty-six of 33 patients in Group I and 42 of 50 patients in Group II believed they had received spinal endoscopy. Two patients in Group I and two patients in Group II were unable to theorize as to which procedure they may have received. The remaining patients guessed the wrong treatment. There was no significant difference among the groups as to whether they believed they had received the endoscopy or epidural steroid injection.

\section{Adverse events}

There was one case of subarachnoid block in Group II, identified after completion of the procedure and injection of local anesthetic and steroid. No adverse effects were noted in this patient. There were no other adverse events noted.

\section{Discussion}

This randomized, double-blind, controlled evaluation demonstrated that following spinal endoscopic adhesiolysis a significant proportion of patients with chronic, refractory low back and lower extremity pain experienced significant pain relief $(\geq 50 \%)$ at 3 months $(80 \%), 6$ months $(56 \%)$, and at 12 months $(48 \%)$, compared to the control group with only $33 \%$ of patients showing improvement at 1 month, and none thereafter. Associated improvements in VAS scores, Oswestry Disability Index, range of motion, and psychological status were also noted as compared to baseline measurements and results of the control group. These results are important in that the patients in this study represented a subset of patients who have not only failed multiple conservative modalities of management but also lacked significant, or long-term, 
response to fluoroscopically-directed epidural steroid injections and one-day percutaneous adhesiolysis.

Numerous studies have evaluated the effectiveness of spinal endoscopic adhesiolysis [24-29,31]; however, these studies utilized heterogenous inclusion criteria. Igarashi et al [29] evaluated patients with degenerative lumbar spinal stenosis. Manchikanti et al [26] evaluated only patients with a history of previous surgical intervention. In another study, Manchikanti et al [27] included patients who had not previously undergone surgery (a total of $16 \%)$. Dashfield et al [31] included only non-surgical patients. Geurts et al [24] reported results of spinal endoscopic adhesiolysis in 20 patients suffering with chronic low back pain. They reported $>50 \%$ reduction in pain in $40 \%$ of the patients at 3 months, and $35 \%$ at 6,9 , and 12 months. Richardson et al [25] reported results in 38 patients, with 19 of those patients identified with failed back surgery syndrome. They reported significant improvement based on Visual Analogue Scale and functional abilities. However, they have not reported data with regards to the proportion of patients with sustained relief at various time periods. Manchikanti et al $[26,27]$ in two different studies, reported $75 \%$ relief at 3 months, $40 \%$ at 6 months, and $22 \%$ at 12 months in post-lumbar laminectomy patients; and, in a heterogenous group of patients including both post laminectomy and non-surgical patients, $52 \%$ of the patients at 3 months, $21 \%$ of the patients at 6 months, and 7\% of the patients after 12 months. Igarashi et al [29] evaluated 58 patients with degenerative lumbar spinal stenosis, dividing them into two groups based on the presenting symptoms of either a monosegmental group $(\mathrm{n}=34)$ or a multisegmental group $(n=24)$. They showed that relief of low back pain was observed up to 12 months after epiduroscopy in both groups, whereas relief of leg pain was evident up to 12 months after epiduroscopy in the monosegmental group, and up to 3 months after epiduroscopy in the multisegmental group. Dashfield et al [31] compared caudal epidural steroid injections with targeted steroid placement during spinal endoscopy for chronic sciatica in a prospective, randomized, double-blind trial. They randomized 60 patients with a 6-to 18-month history of sciatica to either a targeted epidural local anesthetic and steroid placement with a spinal endoscope, or caudal epidural local anesthetic and steroid placement. They defined sciatica as pain in the distribution of lumbar nerve root, accompanied by neurosensory and motor deficits, with or without back pain. They excluded patients with history of previous spinal surgery, coagulopathy, progressive motor neuron disorders or peripheral vascular disease, and patients receiving epidural corticosteroid injections within 3 months. No significant differences were found between the groups for any of the measures at any time. However, there were significant differences within both groups com- pared with pre-treatment values. The results of the present evaluation may not be compared to either the studies by Igarashi et al [29] or by Dashfield et al [31].

Igarashi et al [29] evaluated patients only with spinal stenosis. One-day percutaneous adhesiolysis also was shown to be effective in refractory spinal stenosis [44]. However, Igarashi et al [29] did not treat their patients with spinal stenosis with percutaneous adhesiolysis, which is considered as a safer and more effective procedure. The study by Dashfield et al [31] was performed in patients who were not expected to have epidural fibrosis and who had not been treated with either epidural steroid injections or with 1-day or 3-day percutaneous adhesiolysis. Consequently, there was no significant difference noted between caudal epidural steroid injections and targeted steroid placement with spinal endoscopy. In clinical practice in the United States, invasive intervention with spinal endoscopy as an initial treatment is not widely accepted.

The most common and worrisome complications of spinal endoscopy with adhesiolysis and injection of corticosteroids are related to dural puncture, spinal cord compression, intravascular injection, vascular injury, cerebral vascular or pulmonary embolus, infection, steroids, instrumentation with endoscope, and administration of high volumes of fluids potentially resulting in excessive epidural hydrostatic pressures, resulting in blindness, neurapraxia, numbness, intravascular injections, brain damage, and death [23-30,45-58]. Even though no major complications have been noted in this study, it is recommended that all precautions be undertaken, along with exhaustion of other modalities of treatments prior to embarking on spinal endoscopic adhesiolysis considering the safety and cost. The cost of the endoscope and the procedure are higher than either caudal epidural steroid injections or 1-day or 3-day percutaneous adhesiolysis procedure. The safety and effectiveness of 1-day and 3-day percutaneous adhesiolysis has been demonstrated $[21,22]$.

The present evaluation utilized early unblinding in some patients, did not include a placebo group, and adapted a randomization ratio of 2:3 instead of 1:1. Considering the difficulties of recruiting patients to a double-blind trial, the authors considered the best way to recruit patients and give them a reasonable level of comfort was to offer additional treatment(s) if they failed the study, rather than allowing them to suffer for a year. Based on this allocation, the authors managed to include an acceptable number of patients. The control group for the study was not a true placebo group since interventions of caudal epidural steroid injections were used; nevertheless, the injections were ineffective in these patients. One of the objectives of the study was to demonstrate whether epi- 
dural steroid injections administered after adhesiolysis are effective as opposed to traditional or fluoroscopicallydirected epidural steroid injections. In addition, this also served to provide a level of comfort to patients enrolled in the study since they knew they would receive some type of active treatment rather than a placebo. The authors believed that this type of randomization with a control group receiving standard treatment to be more effective and provide optimal results. A randomization process with a 2:3 ratio was selected to convince patients to enroll in the study, as they would have a higher chance of being included in a treatment group rather than a control group. The statistical validity was maintained throughout the study and an intent-to-treat analysis was incorporated in the study.

Trials of healthcare interventions are often described as either explanatory or pragmatic $[40,41]$. Explanatory trials generally measure efficacy - the benefit a treatment produces under ideal conditions. Consequently, explanatory trials often use carefully-defined subjects in a well-controlled research setting. By contrast, pragmatic trials, also known as practical clinical trials, measure effectiveness benefit the treatment produces in routine clinical practice. Tunis et al [40] commented on the prevalence and significance of gaps in knowledge about clinical effectiveness of interventions and suboptimal evidence available to answer the critical questions. Most systematic reviews performed in interventional pain management include studies providing data not applicable to patients treated in typical practice settings. Consequently, limited quantity and quality of available scientific information impedes the efforts of public and private health insurers in developing evidence-based coverage policies for many new and existing technologies $[59,60]$.

The substantial differences between explanatory and pragmatic trials illustrate a paradigm shift to clinical practice. Patient selection in an explanatory approach is based on the principles of homogenous population, primarily aiming to further scientific knowledge. However, in a pragmatic or practical clinical trial, the design reflects variations between patients that occur in real life clinical settings, and aims to inform choices between treatments. The authors consider this trial to be close to pragmatic or practical rather than explanatory. Even with appropriate randomization, the major focus of clinical research in the modern era of medicine, multiple other sources of bias may affect results. In this study, independent assessment was utilized. However, without a placebo treatment, in pragmatic approaches, the treatment response is the total difference between two treatments, including both treatment and associated placebo effects, as this will best reflect the likely clinical response in practice $[22,30,58,61$ 65]. Practical clinical trials are expected to best address questions about the risks, benefits, and cost of an intervention as they would occur in routine clinical practice [41]. Thus, the most distinctive features of practical clinical trials are that they select patients from practices, either simulating actual practices or actual clinical practices. In addition, practical clinical trials often are designed to compare viable alternative clinical strategies. This study achieves both the distinctive features of practical clinical trials by selecting the population from an actual clinical practice and also by comparing viable alternative clinical strategies.

This procedure may be considered as a replacement for large bore catheter for percutaneous adhesiolysis, as we have not derived any diagnostic information. However, visualization of the scar tissue and freeing of the scar tissue from the nerve root may provide some additional benefit. The present day available catheters for percutaneous adhesiolysis are smaller bore. Consequently, spinal endoscopy with larger bore and improved flexibility appears to have a role. Percutaneous adhesiolysis has been shown to be an effective and safe procedure $[21,22,45,46]$. However this study went beyond percutaneous adhesiolysis and selected the patients after insufficient response after 1-day percutaneous adhesiolysis.

The issue remains for the patients who have had successful relief for 6 months or 12 months with regards to further treatment when pain returns and functional status deteriorates. Based on the present literature, with proper indications and precautions, the procedure may be repeated after approximately 6 months. In addition, the authors believe that even if patients have not responded previously to these procedures, if they have responded initially to spinal endoscopy, they may respond to 1-day or 3-day percutaneous adhesiolysis or even caudal epidural steroid injections. However, published data is not available at present to support this assumption and controlled trials are recommended to evaluate this postulate. Additional effect from spinal endoscopic adhesiolysis may be dependent on hydrostatic pressures created by the administration of sodium chloride solution which is not the case with lesser volume percutaneous adhesiolysis. However, percutaneous adhesiolysis also may be modified to accommodate this feature.

\section{Conclusion}

This controlled trial demonstrates that spinal endoscopic adhesiolysis reduces pain and improves functional and psychological status without adverse effects up to 12 months.

\section{Competing interests}

The author(s) declare that they have no competing interests. 


\section{Authors' contributions}

LM conceived and designed the study, processed the data and wrote the manuscript.

MVB participated in the study's design and revised the manuscript.

JJR participated in its design and collected the clinical data.

VSP performed the statistical analysis.

KSD collected the clinical data.

CDM collected the clinical data.

DEB participated in the procedure.

SRW participated in the procedure.

All authors read and approved the final manuscript.

\section{References}

I. Alkalay RN, Kim DH, Urry DW, Xu J, Parker TM, Glazer PA: Prevention of postlaminectomy epidural fibrosis using bioelastic materials. Spine 2003, 28:1659-1665.

2. Gil K, Frymoyer JW: The management of treatment failure after decompressive surgery, The Adult Spine: Principles and Practice. Edited by: Frymoyer JW. New York: LippincottRaven Publishers; 1991:849-870.

3. Fritsch EW, Heisel J, Rupp $S$ : The failed back surgery syndrome. Reasons, intraoperative findings, and long-term results: A report of 182 operative treatments. Spine 1996, 21:626-633.

4. Ross JS, Robertson JT, Frederickson RC, Petrie JL, Obuchowski N, Modic MT, deTribolet N: Association between peridural scar and recurrent radicular pain after lumbar discectomy: magnetic resonance evaluation. Neurosurgery 1996, 38:855-86I.

5. Hoyland JA, Freemont AJ, Jayson MI: Intervertebral foramen venous obstruction. A cause of periradicular fibrosis? Spine 1989, 14:558-568.

6. Rydevik BL: The effects of compression on the physiology of nerve roots. J Manipulative Physiol Ther 1992, 15:62-66.

7. Songer M, Ghosh L, Spencer D: Effects of sodium hyaluronate on peridural fibrosis after lumbar laminectomy and discectomy. Spine 1990, 15:550-554.

8. North RB, Campbell JN, James CS, Conover-Walker MK, Wang H, Piantadosi S, Rybock JD, Long DM: Failed back surgery syndrome: 5-year follow-up in 102 patients undergoing repeated operation. Neurosurgery 1991, 28:685-690.

9. Dullerud R, Graver V, Haakonsen M, Haaland AK, Loeb M, Magnaes $B$ : Influence of fibrinolytic factors on scar formation after lumbar discectomy. A magnetic resonance imaging followup study with clinical correlation performed 7 years after surgery. Spine 1998, 23:1464-| 469.

10. Pawl RP: Arachnoiditis and epidural fibrosis: The relationship to chronic pain. Curr Rev Pain 1998, 2:93-99.

11. Annertz M, Jönsson B, Stromquist B, Holtas S: No relationship between epidural fibrosis and sciatica in the lumbar postdiscectomy syndrome: A study with contrast-enhancement magnetic resonance imagery in symptomatic and asymptomatic patients. Spine 1995, 20:449-453.

12. Cervellini P, Curri D, Volpin L, Bernardi L, Pinna V, Benedetti A: Computed tomography of epidural fibrosis after discectomy. A comparison between symptomatic and asymptomatic patients. Neurosurgery 1988, 6:710-713.

13. Coskun E, Suzer T, Topuz O, Zencir M, Pakdemirli E, Tahta K: Relationships between epidural fibrosis, pain, disability, and psy- chological factors after lumbar disc surgery. Eur Spine J 2000, 9:218-223.

14. Benoist M, Ficat $C$, Baraf $P$, Cauchoix J: Postoperative lumbar epiduro-arachnoiditis: Diagnosis and therapeutic aspects. Spine 1980, 5:432-436.

15. Cauchoix J, Ficat $C$, Girard B: Repeat surgery after disc excision. Spine 1978, 3:256-259.

16. Phillips FM, Cunningham B: Managing chronic pain of spinal origin after lumbar surgery. Spine 2002, 27:2547-2553.

17. Larocca $\mathrm{H}, \mathrm{MacNab}$ I: The laminectomy membrane. J Bone Joint Surg $B r$ 1974, 56B:545-550.

18. McCarron RF, Wimpee MW, Hudkins PG, Laros GS: The inflammatory effects of nucleus pulposus: $A$ possible element in the pathogenesis of low back pain. Spine 1987, I 2:760-764.

19. Cooper RG, Freemont AJ, Hoyland JA, Jenkins JP, West CG, Illingworth KJ, Jayson MI: Herniated intervertebral disc-associated periradicular fibrosis and vascular abnormalities occur without inflammatory cell infiltration. Spine 1995, 20:59|-598.

20. Parke WW, Watanabe $R$ : Adhesions of the ventral lumbar dura. Adjunct source of discogenic pain? Spine 1990, 15:300-303.

2I. Heavner JE, Racz GB, Raj P: Percutaneous epidural neuroplasty. Prospective evaluation of $0.9 \% \mathrm{NaCl}$ versus $10 \% \mathrm{NaCl}$ with or without hyaluronidase. Reg Anesth Pain Med 1999, 24:202-207.

22. Manchikanti L, Rivera JJ, Pampati V, Damron KS, MCManus CD, Brandon DE, Wilson SR: One-day lumbar epidural adhesiolysis and hypertonic saline neurolysis in treatment of chronic low back pain: A randomized, double-blind trial. Pain Physician 2004, 7:177-186.

23. Manchikanti L, Singh V: Epidural lysis of adhesions and myeloscopy. Curr Pain Headache Rep 2002, 6:427-435.

24. Geurts JW, Kallewaard JW, Richardson J, Groen G]: Targeted methylprednisolone acetate/hyaluronidase/clonidine injection after diagnostic epiduroscopy for chronic sciatica: A prospective, I-year follow-up study. Reg Anesth Pain Med 2002, 27:343-352.

25. Richardson J, McGurgan P, Cheema S, Prasad R, Gupta S: Spinal endoscopy in chronic low back pain with radiculopathy: $A$ prospective case series. Anaesthesia 200I, 56:454-460.

26. Manchikanti L, Pampati V, Bakhit CE, Pakanati RR: Non-endoscopic and endoscopic adhesiolysis in post lumbar laminectomy syndrome. A one-year outcome study and cost effective analysis. Pain Physician 1999, 2:52-58.

27. Manchikanti $L$ : The value and safety of epidural endoscopic adhesiolysis. Amer J Anesthesiol 2000, 27:275-279.

28. Krasuski P, Poniecka AW, Gal E, Wali A, Truong A, Hart AM: Epiduroscopy: Review of techniques and results. Pain Clinic 200I, 13:71-76.

29. Igarashi T, Hirabayashi Y, Seo N, Saitoh K, Fukuda H, Suzuki H: Lysis of adhesions and epidural injection of steroid/local anesthetic during epiduroscopy potentially alleviate low back leg pain in elderly patients with lumbar spinal stenosis. $\mathrm{Br} J$ Anesth 2004, 93:18I-187.

30. Manchikanti L, Rivera J, Pampati VS, Damron KS, Beyer CD, Brandon $D E$, Wilson SR: Spinal endoscopic adhesiolysis in the management of chronic low back pain: A preliminary report of a randomized, double-blind trial. Pain Physician 2003, 6:259-268.

31. Dashfield AK, Taylor MB, Cleaver JS, Farrow D: Comparison of caudal steroid epidural with targeted steroid placement during spinal endoscopy for chronic sciatica: a prospective, randomized, double-blind trial. BrJ Anaesth 2005, 94:5।4-5I9.

32. Systems to rate the strength of scientific evidence: Evidence Report/ Technology Assessment No. 47 University of North Carolina; Agency for Healthcare Research and Quality. AHRQ Publication No. 02-E016 2002.

33. The Standards of Reporting Trials Group: A proposal for structured reporting of randomized controlled trials. JAMA 1994, 272:1926-1931.

34. van Tulder M, Furlan A, Bombardier C, Bouter L: Editorial Board of the Cochrane Collaboration Back Review Group. Updated method guidelines for systematic reviews in the Cochrane collaboration back review group. Spine 2003, 28: $1290-1299$.

35. Nelemans PJ, deBie RA, deVet HCW: Injection therapy for subacute and chronic benign low back pain. Spine 200I, 26:50I-5I 5 .

36. Niemisto L, Kalso E, Malmivaara A, Seitsalo S, Hurri H, Cochrane Collaboration Back Review Group: Radiofrequency denervation for neck and back pain: a systematic review within the frame- 
work of the Cochrane collaboration back review group. Spine 2003, 28: $1877-1888$

37. Koes BW, Bouter LM, van der Heijden GJMG: Methodological quality of randomized clinical trials on treatment efficacy in low back pain. Spine 1995, 20:228-235.

38. Koes BW, Scholten RJPM, Mens JMA, Bouter LM: Epidural steroid injections for low back pain and sciatica. An updated systematic review of randomized clinical trials. Pain Digest 1999 , 9:24|-247.

39. van Tulder MW, Koes BW, Bouter LM: Conservative treatment of acute and chronic nonspecific low back pain: A systematic review of randomized controlled trials of the most common interventions. Spine 1997, 22:2 I 28-2156.

40. Tunis SR, Stryer DB, Clancy CM: Practical Clinical Trials. Increasing the value of clinical research for decision making in clinical and health policy. JAMA 2003, 290:1624-1632.

4I. Roland M, Torgerson DJ: What are pragmatic trials? BMJ 1998, 3 | 6:285

42. Tollison CD, Langely JC: Pain Patient Profile (P-3®) Manual National Computer Systems, Minneapolis; 1995.

43. Fairbank JC, Pynsent PB: The Oswestry Disability Index. Spine 2000, 25:2940-2953.

44. Manchikanti L, Pampati VS, Rivera JJ. Fellows B, Beyer CD, Damron $\mathrm{KS}$, Cash KA: Effectiveness of percutaneous adhesiolysis and hypertonic saline neurolysis in refractory spinal stenosis. Pain Physician 200I, 4:366-373.

45. Manchikanti L, Bakhit CE: Percutaneous lysis of epidural adhesions. Pain Physician 2000, 3:46-64.

46. Viesca C, Racz G, Day M: Spinal techniques in pain management: lysis of adhesions. Anesthesiol Clin North Am 2003, $21: 745-766$

47. Saberski L, Brull S: Spinal and epidural endoscopy: A historical review. Yale J Bio Med 1995, 68:7-I5.

48. Bromage RP, Benumof JL: Paraplegia following intracord injection during attempted epidural anesthesia under general anesthesia. Reg Anesth Pain Med 1998, 23: 104-107.

49. MacLean CA, Bachman DT: Documented arterial gas embolism after spinal epidural injection. Ann Emerg Med 200I, 38:592-595.

50. Mateo E, Lopez-Alarcon MD, Moliner S, Calabuig E, Vivo M, De Andres J, Grau F: Epidural and subarachnoid pneumocephalus after epidural technique. Eur J Anesthesiol 1999, 16:413-417.

51. Katz JA, Lukin R, Bridenbaugh PO, Gunzenhauser L: Subdura intracranial air: An unusual cause of headache after epidural steroid injection. Anesthesiology 1991, 74:615.

52. Knight JW, Cordingley J], Palazzo MG: Epidural abscess following epidural steroid and local anesthetic injection. Anaesthesia 1997, 52:576-578.

53. Tabandeh $\mathrm{H}$ : Intraocular hemorrhages associated with endoscopic spinal surgery. Am J Ophthalmol 2000, I 29:688-690.

54. Kusher FH, Olson JC: Retinal hemorrhage as a consequence of epidural steroid injection. Arch Opthalmol I995, I I 3:309-3 I3.

55. Purdy EP, Gurjit SA: Vision loss after lumbar epidural steroid injection. Anesth Analg 1998, 86:1 19-122.

56. Sandberg DI, Lavyne MH: Symptomatic spinal epidural lipomatosis after local epidural corticosteroid injections: Case report. Neurosurgery 1999, 45:162-165.

57. Manchikanti L: Role of neuraxial steroids in interventional pain management. Pain Physician 2002, 5:182-199.

58. Manchikanti L, Staats PS, Singh V, Schultz DM, Vilims BD, Jasper JF, Kloth DS, Trescot AM, Hansen HC, Falasca TD, Racz GB, Deer T, Burton AW, Helm S, Lou L, Bakhit CE, Dunbar EE, Atluri SL, Calodney AK, Hassenbusch S, Feler CA: Evidence-based practice guidelines for interventional techniques in the management of chronic spinal pain. Pain Physician 2003, 6:3-80.

59. Garber AM: Evidence-based coverage policy. Health Aff (Milwood) 200I, 20:62-82

60. Tunis R, Kang JL: Improvements in Medicare coverage of new technology. Health Aff (Milwood) 200I, 20:83-85

6I. Manchikanti L, Manchikanti KN, Damron KS, Pampati VS: Effectiveness of cervical medial branch blocks in chronic neck pain: $A$ prospective outcome study. Pain Physician 2004, 7:195-202.

62. Manchikanti L, Pampati VS, Bakhit CE, Rivera J], Beyer CD, Damron KS, Barnhill RC: Effectiveness of lumbar facet joint nerve blocks in chronic low back pain: A randomized clinical trial. Pain Physician 200I, 4: I01-II7.
63. Manchikanti L, Cash KA, Moss TL, Rivera J, Pampati VS: Risk of whole body radiation exposure and protective measures in fluoroscopically guided interventional techniques: A prospective evaluation. BMC Anesthesiol 2003, 3:2.

64. Manchikanti L, Pampati VS, Rivera JJ, Beyer CD, Damron KS, Barnhill RC: Caudal epidural injections with Sarapin or steroids in chronic low back pain. Pain Physician 200I, 4:322-335.

65. Bogduk N, Karasek M: Two-year follow-up of a controlled trial of intradiscal electrothermal annuloplasty for chronic low back pain resulting from internal disc disruption. Spine J 2002 , 2:343-350.

\section{Pre-publication history}

The pre-publication history for this paper can be accessed here:

http://www.biomedcentral.com/1471-2253/5/10/prepub
Publish with Bio Med Central and every scientist can read your work free of charge

"BioMed Central will be the most significant development for disseminating the results of biomedical research in our lifetime. "

Sir Paul Nurse, Cancer Research UK

Your research papers will be:

- available free of charge to the entire biomedical community

- peer reviewed and published immediately upon acceptance

- cited in PubMed and archived on PubMed Central

- yours - you keep the copyright
BioMedcentral 